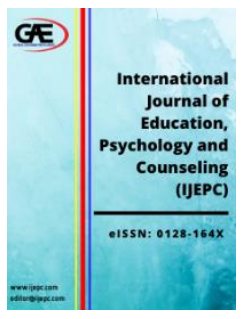

\author{
INTERNATIONAL JOURNAL OF \\ EDUCATION, PSYCHOLOGY \\ AND COUNSELLING \\ (IJEPC) \\ $\underline{\text { wWw.ijepc.com }}$
}

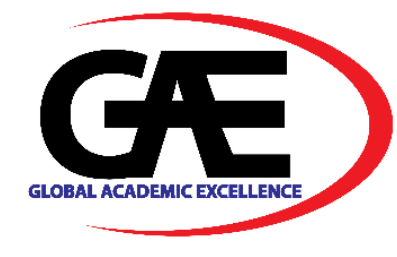

\title{
THE FEASIBILITY OF A PERSONAL LEARNING ENVIRONMENT (PLE) TO SUPPORT ACADEMIC WRITING: ESL PRE-SERVICE TEACHERS' PERSPECTIVES
} \author{
Pudin ${ }^{4}$ \\ 1 Faculty of Psychology and Education, Universiti Malaysia Sabah, Malaysia \\ Email: noraini.said@ums.edu.my \\ 2 Faculty of Psychology and Education, Universiti Malaysia Sabah, Malaysia \\ Email: megawati.s@ums.edu.my \\ 3 Faculty of Psychology and Education, Universiti Malaysia Sabah, Malaysia \\ Email: nzaitun@ums.edu.my \\ 4 Pusat Penataran Ilmu dan Bahasa, Universiti Malaysia Sabah \\ Email: chelster@ums.edu.my \\ Corresponding Author
}

Noraini Said ${ }^{1}$, Megawati Soekarno², Nik Zaitun Nik Mohamed ${ }^{3}$, Chelster Sherralyn Jeoffrey

\section{Article Info:}

Article history:

Received date: 11.09 .2021

Revised date: 10.10 .2021

Accepted date: 15.11 .2021

Published date: 30.11 .2021

\section{To cite this document:}

Said, N., Soekarno, M., Nik Mohamed, N. Z., \& Pudin, C. S. J. (2021). The Feasibility of a Personal Learning Environment (PLE) to Support Academic Writing: ESL PreService Teachers' Perspectives. International Journal of Education, Psychology and Counseling, 6 (43), 110-121.

DOI: $10.35631 / \mathrm{IJEPC} .643010$

\begin{abstract}
:
A recent trend has highlighted the need for a personal learning environment (PLE) in education as a system that helps learners take control of and manage their own learning. The current system which focuses on standardized learning support in the form of Learning Management System (LMS) is seen as restrictive and does not allow to accommodate the different needs of learners. Therefore, more language educators have started developing their own PLEs by focusing on two crucial elements: supporting learners' needs and allowing more learner control. This paper presents an attempt to explore ESL pre-service teachers' experience via PLE designed to support their writing needs. The researchers hoped that such a positive experience would influence the teachers' pedagogical strategies and approaches in their teaching once they go into practice. In this qualitative case study, thirty-six third year ESL pre-service teachers at a tertiary education institution embarked on a fourteen-week course via the PLE. Qualitative data were gleaned from focus group discussion transcripts and written reflections. Thematic analysis was used to analyse the qualitative data. Overall, students have positive perceptions towards the PLE by detailing its benefits and usefulness. They also narrated some challenges and proposed suggestions to ensure prolonged engagement. The findings give support to the use of PLE, especially the instructor-made innovation for teaching and learning which allows more learner control and access.
\end{abstract}




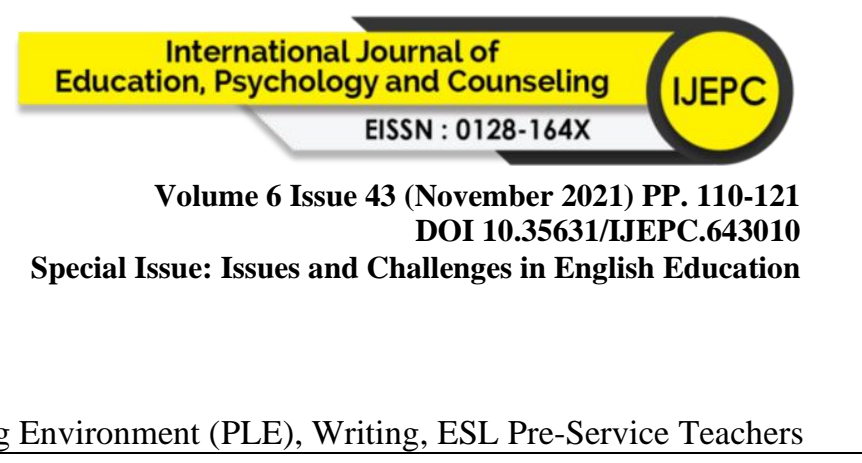

\section{Introduction}

Since 2020, literature has captured the boost in the number of transitions from the traditional classroom into e-learning, especially in the English as a Second Language (ESL) higher education context (Agusintadewi, N. K., Mahastuti, M., Agung, A., \& Aritama, N., (2021); Bakar, Osman, Rahim, and Rahman (2021); Rahim, Osman, Musa and Rahman., (2021); Wellapan and Liyen, (2021). The pandemic of COVID19 which has thrown the world into a complete disorder in 2020 due to the shutdown on mass mobilisation and restricted social interaction has been identified as the catalyst to the boom in e-learning. Recent studies illustrated struggles and woes by instructors and learners in language learning through elearning. Tobi, Osman, and Bakar (2021) studied the prevalent challenge in synchronous sessions of students not switching camera in their language proficiency course. The findings revealed that lack of internet data, poor internet connection, social norms, not being physically presentable, and not being comfortable to be looked at by peers were among the actual reasons. Apart from that, Chen (2020) highlighted that the ESL students lack the skills to search for information online, which is deemed as a serious concern as in e-learning as students have to be independent in order to accomplish their tasks and gain understanding. Her study discovered that the subjects lacked the specific skill related to self-awareness of searching orientation when searching English information online. These crucial findings therefore imply that instructor support to guarantee successful e-learning is mandatory.

The quest to develop the optimal learning environment is an ongoing process as instructors and developers strive to provide the best learning experience for learners. Recent studies captured language instructors' experimentation with varying strategies and latest educational apps and tools to provide excellent learning environment for their studies. For instance, in Bakar et al., (2021), the ESL instructors experimented with Madlipz, a mobile application which allows students to dub their voices and create their own dialogue or monologue based on the video clips that they chose. Their attempt was rewarded with promising results of improved pronunciation and a marked boost in confidence in their subjects. In another study, Wellapan and Liyen (2021) highlighted the importance of giving flexibility to learners in taking charge of their individual learning through flipped classroom strategy. The findings of the study showed increased level of preparedness in synchronous sessions and improved overall perception towards learning. The students were also said to be more open to the strategy for other hands-on or practical courses. Therefore, motivated by the concerted efforts by ESL educators worldwide in providing language learners a positive learning experience, the researchers developed a personal learning environment (PLE) to the students affected in this pandemic to answer this essential question: What were the ESL pre-service teachers' perceptions towards the PLE in supporting them to accomplish their writing?

\section{Literature Review}

The concept of personal learning environment (PLE) resonates with the ideal expectations of learning. It can be distinguished from the use of Learning Management Systems (LMS) which are often perceived as a standardized, one-size-fits-all solution, which realistically 


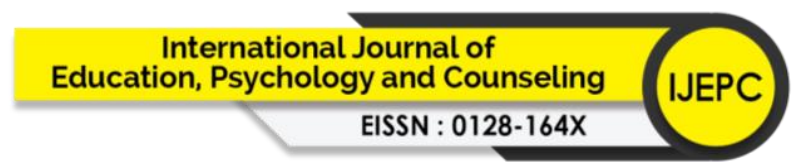

Volume 6 Issue 43 (November 2021) PP. 110-121

DOI 10.35631/IJEPC.643010

Special Issue: Issues and Challenges in English Education

does not accommodate all learners due to learner diversity. Therefore, capitalizing on PLE can be seen as a promising pedagogical approach to integrate formal and informal learning in social media and support student self-regulated learning. Literature on PLE can be traced back to as early as 2000s in the work of Attwell (2007). PLE, according to him can best be described as the following:

\begin{abstract}
"The idea of a Personal Learning Environment recognises that learning is continuing and seeks to provide tools to support that learning. It also recognises the role of the individual in organising their own learning. Moreover, the pressures for a PLE are based on the idea that learning will take place in different contexts and situations and will not be provided by a single learning provider. Linked to this is an increasing recognition of the importance of informal learning.
\end{abstract}

Attwell ( 2007, p.2)

In other words, PLEs are environments where learners are assisted with tools and resources which allow them to interact in a very flexible way. Apart from that, PLEs are often seen to bring out an important result of learning and help build habits of independent learning. Siemens (2007) perceived that PLE was a collection of tools brought together under the conceptual notion of openness, interoperability, and learner control. These three concepts often associated with PLE, are some of the highlights in PLE-related studies. For instance, Agusintadewi et al. (2021) highlighted the use of social media tools in the creation of PLE in order to encourage knowledge sharing and boost creativity. Their study also leveraged on the use of social media in the acquisition of information, and submission of assignments. Their subjects had positive attitudes towards the use of social media in their learning environment and considered it student friendly. In a different study, Trang (2020) constructed a rhizomatic online PLE model to enrich ESL learners' learning experience to learn listening skills. The PLERN model made use of free online resources which allow easy access regardless of time and place restrictions. The findings show that the PLERN was able to produce desired outcomes when optimally used.

Drawn by the success of previous studies, the researchers in this study embarked on a project to develop a PLE as an online tool to support ESL learners' or pre-service teachers' academic writing needs and evaluated its impact based on the learners' perspectives. This PLE is a portal which consists of six important tools for writing and online collaboration such as external resources (evaluated Internet links according to categories), writing portfolio (database for creation, storing, and retrieval of writing drafts), forum, chat, personal messaging system, and a personal reflective tool (CNotes). Figure 1 shows the screenshot of the PLE used in this study. The PLE is named as The Writing Portal to showcase its primary focus on supporting academic writing by leveraging on the five-phase writing process: plan, draft, revise, edit and publish. Initially, PLE version 1.0 was developed in 2012 and tested on 16 ESL pre-service teachers, which yielded a huge success in improving learners' writing experience (Lee et al., 2016). The second version underwent a major cosmetic overhaul by employing modular look, but still retaining all tools/functions from version 1.0. 


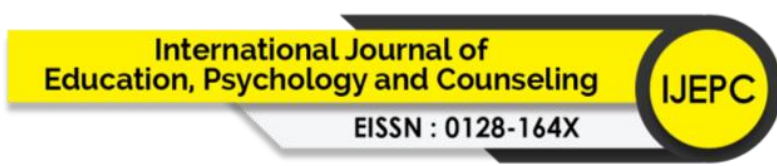

Volume 6 Issue 43 (November 2021) PP. 110-121

DOI 10.35631/IJEPC.643010

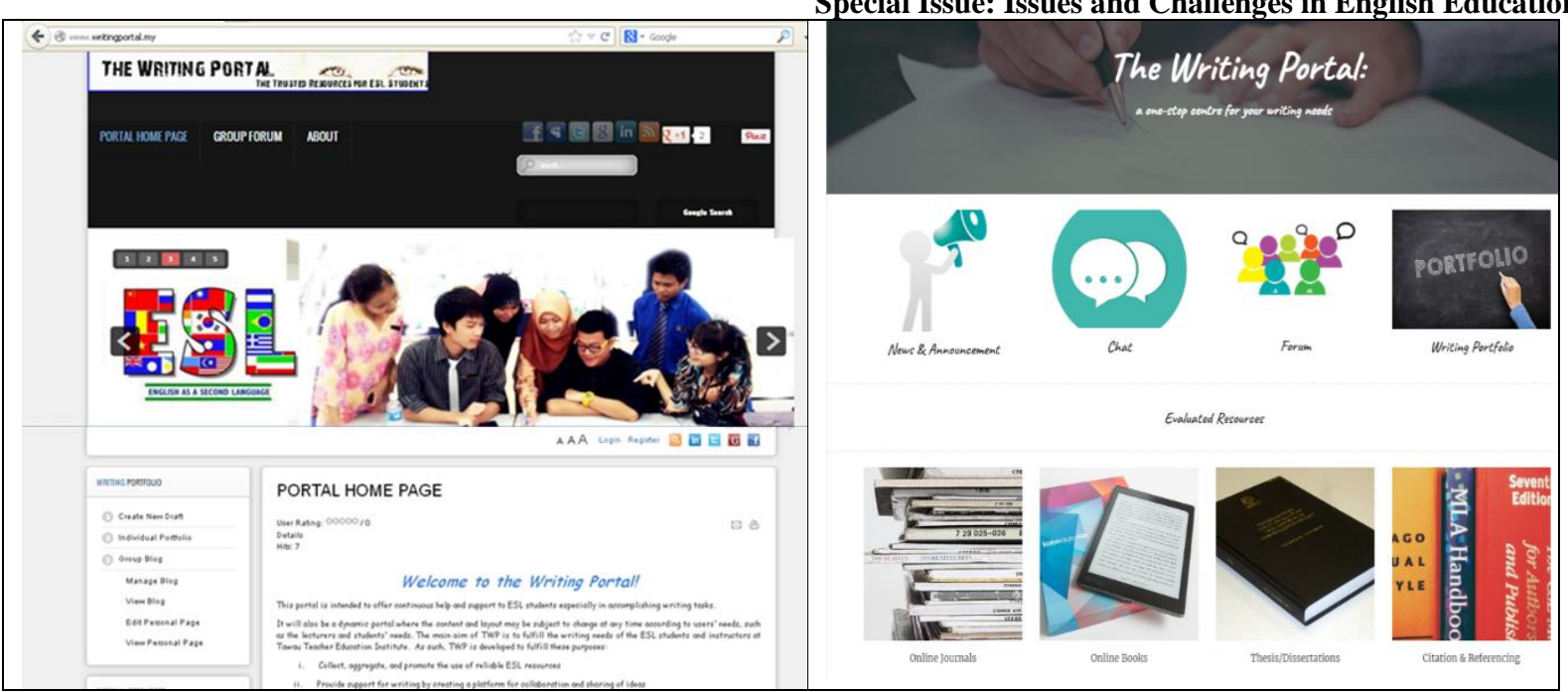

Special Issue: Issues and Challenges in English Education

Figure 1: PLE Version 1.0 and 2.0

\section{Methodology}

This qualitative case study explored the experience and perceptions of thirty-six pre-service ESL teachers enrolled in an undergraduate course who consented to take part in this fourteenweek project. In week 1, they were briefed on how to use the PLE in order to accomplish written coursework. They spent the remaining weeks on completing group report and two individual assignments. One of the researchers acted as the course instructor, while the others acted as proctors to monitor students' progress and give technical assistance. Task/formative reflections, focus group discussion, and summative reflection served as qualitative data sources to answer the research questions.

\section{Data Sources}

Qualitative data was obtained from focus group sessions. Participants decided and formed their own group of five to eight members each. At the end of the course, the researchers conducted one focus group session for all groups. The session was done to explore participants' experiences with the PLE during writing and investigate how participants perceive the PLE as a support tool in undergoing all stages of writing process. Topics of discussion included how the PLE complements the stages in writing process, benefits of using the PLE in writing, problems/ challenges faced, and suggestions for improvement of PLE.

Participants' summative reflective journal, which was completed after they finished all writing tasks, is another data source for this study. The students created their reflection in the individual portfolio section to reflect on their experience by asking these questions themselves at the end of the coursework: How does the PLE complement my writing journey? What functions of the PLE do I find useful and least useful? What problems did I encounter? How could they be overcome in the future?

\section{Data Analysis}

Based on two sources of reflections and focus group interview transcripts, data were thematically analysed to explore students' perceptions towards PLE in relation to their writing experiences during the written coursework. 


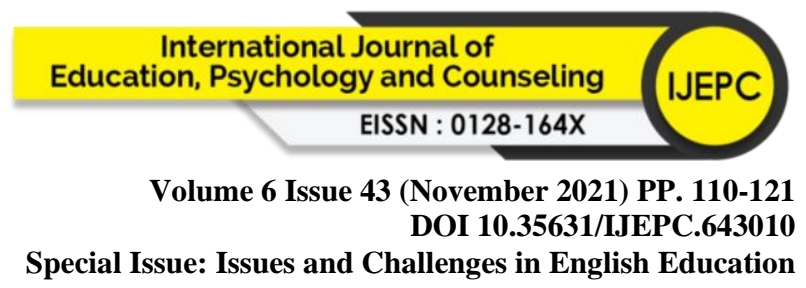

\title{
Findings \& Discussion
}

\section{Benefits and Usefulness of PLE}

In the summative reflections and focus group interviews, students discussed about how they evaluated PLE in relation to their writing experience. All thirty-six summative reflections revealed positive feedback towards the use of PLE. Most of the excerpts detailed how PLE supported them throughout the writing process. The following excerpt shows how a student felt about PLE. She highlighted the benefits of using PLE as a starting point to mine relevant sources of information and a platform of collaboration.

\begin{abstract}
"PLE is one new approach for students to exchange knowledge and ideas. For me, the PLE really help me in completing the coursework. This provides me with more resources compare to my previous sources. With this PLE, the processes of completing the coursework become easier from planning, drafting, revising, editing and lastly publishing the task... Thanks to the portal, it provide me new platform where I can discuss with my friends and lecturers anytime. PLE provides me with new experience where this was the first sites that I used closely related to my coursework. I never used such sites before thus it provide me with more reliable materials and resources for me to complete the task". $S R \_A R$
\end{abstract}

Some students quoted that they benefited from PLE as it enabled collaboration and sharing of ideas during the written coursework. In addition, it also served as a good source for information. They perceived information in PLE as authentic and reliable.

"Touching on the writing portal, it is the resource centre for my coursework. It provided me with the resources such as journals and articles, plus it also serves as a community gathering where we would discuss and share ideas and opinions on our coursework and resources. In other words, it serves as a point of similarities where we could share and get information regardless of time and places." $-S R \_C L$

"PLE came in handy as $i$ needed reliable resources and information throughout the assignment. The External Resources function in the portal, indeed, provided convenience to all of the users by offering reliable resources such as articles, samples of lesson plans, or information regarding the classroom teaching and learning”. - SR_LI

Some also attributed the benefits of PLE as a tool for them to keep track of their progress. Besides, they also felt that their writing process became more organized and systematic.

"PLE complement my writing journey by acting as a solid track for me to follow along the journey". SR_GR

"The PLE helps me a lot in completing the tasks given. Providing relevant resources, examples on certain task and helping me in planning my task better to be completed in time. As well as helping me to be more organized and systematic in my writing. ".-SR_LV

In the focus group interviews, the discussion on the benefits of PLE was done on specific functions, unlike summative reflections where participants summarized their evaluation of PLE in overall. In the following excerpt, members of the group complimented and recommended the use of External Resources in writing tasks. They seemed to be impressed with the exhaustive number of resources available to them to choose from. 


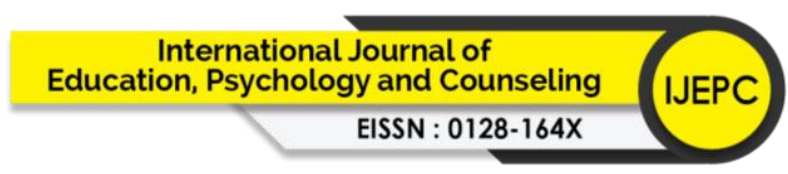

Volume 6 Issue 43 (November 2021) PP. 110-121

DOI 10.35631/IJEPC.643010

BN External Resources?

Special Issue: Issues and Challenges in English Education

MM This is a very good function.

MM This is the only function that attracts me to use the portal, initially.

BN Why?

MM It has provided us a lot of links and files.

CS I've seldom use it before.

ALL Oh my God! You should use it more often!

The articles...

MM I found my article through this function; External Resources... I got it there, because I found it reliable.

BN There's a lot kan.

Similar to summative reflection, some students were also found to elaborate how PLE complemented their writing process in this excerpt:

BN How does PLE complement all the stages in the writing process?

MM Because in every stages... because for example; planning... research from reliable resources... drafting we go to drafting portfolio and write and draft lah... and put a main point... okay, next..

CS Revising, okay... you read it again and then editing... okay before editing... we're like, we share it with our friends and then they comment and we edit again and then publish...

BN Just publish... and everyone can view it and comment again.

FG1

The strong points of PLE are the functions that enable collaboration through the communication tools, and peer feedback in the writing portfolio. Students were also found to evaluate the functions which they felt as most useful. Based on 53 quotations coded in the two sources for most useful, there functions of PLE were selected as the most useful functions: External Resources (53), Group Forum (47) and Chat (43). Writing Portfolio was mentioned only once by a participant.

For External Resources, two reasons were given by the students in their summative reflections. The following excerpts detailed the reasons given. In the first excerpt, students highlighted the benefit of External Resources in helping them to generate ideas in writing.

"The function of PLE that I found very useful is on the External Resources. The External Resources help me in getting the ideas and inputs for my writing. ”- $S R \_L V$

The second excerpt emphasizes on the variety of relevant materials that External Resources provided to students.

"The most important functions that I felt was the most important in The Writing Portal was the External Resources as there were a lot of articles and resourceful information. Most of the articles that were related to the coursework were provided in the External Resources. The task was able to be done smoothly with all the lesson planning and the resources of the information obtained were from the trusted site."'-SR_BN

The selection of Group Forum as the most useful functions is mainly due to its capability in providing opportunities for students to collaborate during writing, and also mining for ideas. In his summative reflection, student MM quoted:

"The writing portal function that I feel the most important is the group forum function. This is because through the group forum we can interact with the other users and try to find as much references as possible from the others. They also can share some links about useful resources to me too". 


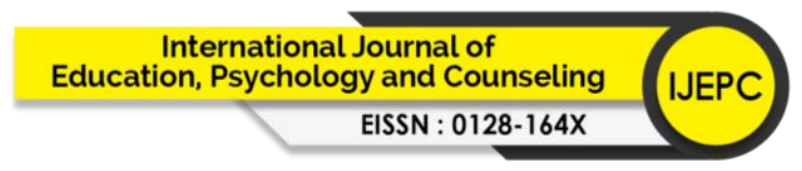

Volume 6 Issue 43 (November 2021) PP. 110-121

DOI 10.35631/IJEPC.643010

Special Issue: Issues and Challenges in English Education

Student LI extended the explanation on how Group Forum complemented her writing journey.

"In here we discuss the topic with the member of PLE. Students and lecturer able to exchange and share their knowledge in here. All of us can talk about a topic as a whole. Everyone voice out opinions, giving suggestions, writing comments and etc. I used this function as my resources especially in my planning, revising and publishing my writing."

The final function that students perceived as important is Chat. All quotations identified its ability in allowing students to casually interact regarding their tasks or other leisure topics. Based on 10 quotations, two functions were perceived as the least useful: CNotes and Personal Messaging System. Students gave three reasons for perceiving CNotes as the least useful. In the first excerpt, student GR felt that he has other applications to write short notes.

“ The one that I feel is least useful is the Cnotes. I don't really use this features as I usually write down my notes in my notebook, use the Sticky Notes features in my computer and put down reminder in my phone if I need to jot important things down". WR_GR

Findings from this study extended more understanding into previous studies in terms of benefits and usefulness of online learning tool or the intervention in writing courses as perceived by students. Students' positive perceptions towards PLE could be explained by their fascination over the new online learning tool, as often the case in other studies (Ismail \& Albakri, (2012); Ismail, Hussin, \& Darus, (2013)). Apart from that, participants viewed such interventions or PLE as a good, authentic, and reliable source of information since it was developed by their own instructors. Other benefits cited by the students also corresponded with positive findings in Popescu (2012) with students mentioning various advantages of the intervention such as the increased confidence and motivation, the opportunity to monitor own progress and compare it to the others, better management of the social media tools such as easier access to accounts and easier to keep track of all tools.

In the present study, students only had one single account to access all different functions in PLE. Students in Popescu (2012) also added usability and attractiveness of the platform as the benefits, which mirrored perceptions of some of the participants in this study. Lin and Kuo (2011) also supported that convenient interface design appealed to the students, which was reflected in students' positive feedback towards PLE, especially Chat and External Resources which were displayed on the home page. They agreed that the simple plug-ins were user-friendly as well and appealed to their interest. They also found the forum function was easy to use and attributed to the use of graphics in their posts, and interesting use of thank-you functions as factors that attracted them to engage in PLE.

\section{Challenges and Problems Faced}

Based on the interview transcripts, many of the challenges faced were attributed to the use of Chat and Group Forum, the functions that they used most often as evidenced by Research Question 1. In addition, the problems were deemed as serious as they could have hampered their collaboration and interaction during the written coursework. In the first group, students complained about their inability to catch up with the posts in Chat since there were too many users. 


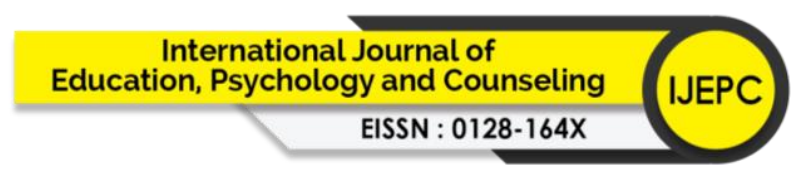

Volume 6 Issue 43 (November 2021) PP. 110-121

DOI 10.35631/IJEPC.643010

Special Issue: Issues and Challenges in English Education

BN The problem is when there's so many users tend to chat at the same time, and then things started getting... like no reply and even when we need to reply someone and then it took like 30 seconds...

MM We are lost in the conversation.

CS We are lost in the conversation, nobody can see me.

In the third group, students also lamented the same problem.

CL Okay, for example?

PT The chat function basically is no... err... wireless connection is problem, and the chat will delay, you will end up blackout...

KG When somebody enter another text then suddenly...

PT Before you read and then...

KG Yeah, man we need to scroll up again.

In addition, the problem was made worse with poor Internet connection, as reported by five participants in their summative reflections. The following excerpt illustrates the problem.

The problem that I encounter when using the PLE was mainly with the connections problems. The internet connections problem was the problem that I encounter when using the PLE as I was unable to loading the site on my computer - SR_GR

The second group in the interview highlighted problems they faced when they were using Chat. The focus of the conversation changed drastically and caused them to lose focus. Group Forum was suggested for more structured conversation.

BN I don't know about group chat. I prefer the group forum.

LI I couldn't use the group chat function.

LE Because if we use the chat function, sometimes we talk about something else.

LI We also cannot see the comments clearly.

GR So we are confused about which topic they are discussing right?

LI Group forum is much more better; more organised.

LE We can attach the files as well. For the chat functions, I don't think we can attach the files for the chat.

Some students also complained how other students misused the Group Forum to post irrelevant pictures. Their annoyance with such behaviour could affect their motivation to use such function. In the following excerpt, students argued about the behaviour of some users who posted irrelevant postings. They had different opinions as some opposed such behaviours, while others accepted them as the norm in online forum.

AR The group forum? But they post a lot of stupid stuffs you know.

DD But it is also beneficial... so fun...

AR When we ask questions there, actually there is someone there who is willing to give answers but some of those people are only posting weird pictures...

CL But that's the point of a group forum actually...

CL You can find the same thing at the other group forum on the Internet.

AR When some people post questions and other people just post silly pictures.

DD Some unrelated...

The more common problem cited by the students was their inability to effectively manage their time as they juggled through many tasks and responsibilities. They also confessed that they actually procrastinated a lot. 


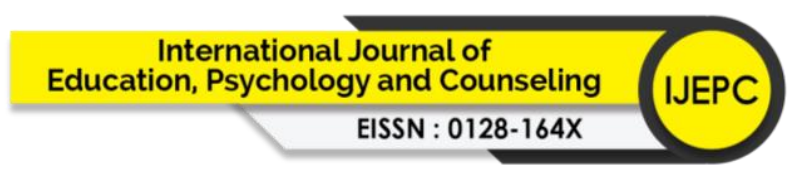

Volume 6 Issue 43 (November 2021) PP. 110-121

DOI 10.35631/IJEPC.643010

SY I personally think it'll waste my time.

Special Issue: Issues and Challenges in English Education

LV It's not wasting time, it is no time... (everyone laughs)

SY Yes because we tend to do our work...

LV Last minute...

CL Yes... procrastinating...

The students admitted that the problems they faced were not only resulted from the use of PLE, but rather caused by their own personal problems especially the lack of time to explore and make the best use of PLE.

Challenges cited by students during the use of PLE in written coursework are similar to the woes highlighted in Ismail and Intan Safinas (2012), Rahim et al., (2021) and Tobi et al., (2021). Poor or slow Internet connection was reported as one of the main problems faced in online learning. The more common problem cited by the students was their inability to effectively manage their time as they juggled through many tasks and responsibilities which led to procrastination in writing tasks. Some students also complained how other students misused the Group Forum to post irrelevant pictures. Their annoyance with such behaviour could affect their motivation to use such function. Other problems were also attributed to the use of forum such as the long waiting time for replies and lack of communication skills (Margaryan et al., 2011).

Problems were also encountered in the use of synchronous communication tool such as chat as the focus of the conversation which changed drastically and caused them to lose focus. This finding is also voiced by Yunus, Salehi, and Chenzi (2012)who found that students were distracted while accomplishing their writing tasks while using Facebook as their writing intervention. Besides that, there were students who complained about the pace of the group and the course in general as they had difficulties to keep up with the technology (Valjataga \& Lannpere, 2010). However, these studies concluded that the benefits outweighed the problems, and that instructors should find solutions to solve the problems by giving clear structure in the use of the tools in writing courses. Falloon (2012) further emphasized that learning experiences seeking student participation through feedback and interaction should be structured accordingly, and guidelines should be established to enable the appropriate use of communication tools

\section{Suggestions}

During the focus group interviews, students gave suggestions on how PLE can be improved for better learning experience even though they generally agreed that the current functions are sufficient for their writing needs as shown in the following excerpt:

CL: Ok, any other suggestions or recommendation?

LV: That's all.. no..

CL: Do you feel like everything is ok now?.

LV: Ya.. everything should be good and enough for our needs

Students expressed their concern so that they would get better learning experience which could lead to prolonged engagement in the future. Most of the suggestions made were on the design aspects so that PLE's visual would be improved. The following excerpts were taken from the transcript: 


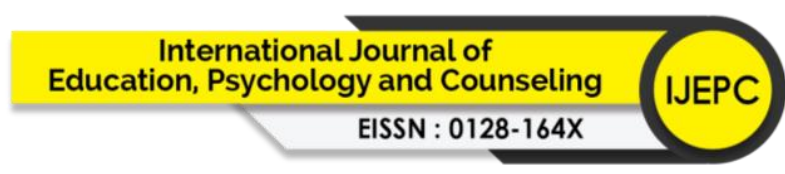

Volume 6 Issue 43 (November 2021) PP. 110-121

DOI 10.35631/IJEPC.643010

BN: $\quad$ And then in terms of visual?

Special Issue: Issues and Challenges in English Education

MM: $\quad$ I think we should make it more lively.

CS: $\quad$ More animation... make it more attractive.

BN: $\quad$ The problem is there's not much user or people...

MM: $\quad$ Maybe they should expose it to more people. Then you expose the usefulness of the portal.

Members in FG3 agreed that they wanted more attractive and simpler design. Apart from that, students seemed to be overwhelmed by the number of the texts that appeared on the home screen.

CL: $\quad$ It should be more interesting but the main feature; the main idea is still there.

PT: You just want it to look cooler?

CL: $\quad$ Yeah, but the function is still there because we know how to use that thing so for

PT: $\quad$ Of course, we do.

KG: $\quad$ But for others, for example, the newbie - I think they are having a hard time to cover this and that.

CL : Yeah, the function should be more simple, more colourful and more accurate; effective.

Students' evaluation of PLE included giving suggestions on how the PLE can be improved. From the researcher's perspective, getting students' input is very important especially for continuous evaluation as students are considered as the main stakeholders in the development of an instructional tool. Although the students did not cite problems with the design of PLE, few suggested that the overall design could be improved by featuring more animation and videos in the homepage so that the visual aspect will be more attractive to them. The present visual could be perceived as too 'heavy' with text since it is intended to be an educational portal. The final suggestion is to enable discussion by topic or thread in Chat, to resemble the function of forum. This particular suggestion may not be possible as chat is a type of synchronous communication technology in the form of instant messaging. Nevertheless, there are possibilities for such function to be found in the growing libraries of plug-ins in the opensource market.

\section{Conclusion}

In general, the introduction of PLE as a support for academic writing show that there are promising possibilities of PLE as a support during the writing process, as well as a conducive collaborative learning environment. The ESL pre-service teachers have strong positive attitudes towards its use in promoting collaboration among themselves, streamlining writing processes by promoting systematic structure in their writing journey, and having high trust in instructors' curated or evaluated external resources useful for their writing tasks. The students' use of PLE is also the embodiment of socio-constructivism, where scaffolding, zone of proximal development (ZPD), the role of more knowledgeable others (MKO) and collaborative learning, are evidenced by findings of this study. Scaffolding was seen in the students' interaction with other students, instructors, and content in PLE. In PLE, interactions occurred between students and other more skilful peers who aided them in developing the learner's skills and strategies. Collectively, PLE seems to be a tool that can provide significant support for students and, inevitably, busy instructors in need of some solutions to support their English language learners within the demands of the curriculum. 


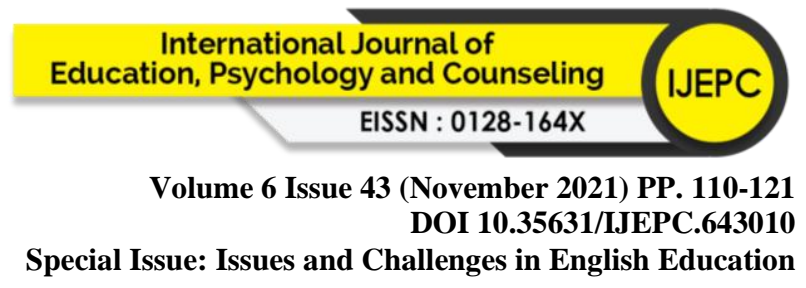

\section{Acknowledgements}

Special Issue: Issues and Challenges in English Education

The authors would like to acknowledge Global Academic Excellence (M) Sdn Bhd, who granted the Publication Grant Scheme for this project.

\section{References}

Agusintadewi, N. K., Mahastuti, M., Agung, A., \& Aritama, N. (2021). The use of social media in the creation of personal learning environment during the \# studyfromhome period. Journal of Education and Learning (EduLearn), 15(February), 78-87. https://doi.org/10.11591/edulearn.v15i1.17581

Attwell, G. (2007). Personal Learning Environments - the future of eLearning ? ELearning Papers, 2(January), 1-8.

Bakar, A. L. A., Osman, W. H., Rahim, S. A., \& Rahman, N. D. (2021). Student Perception In Using Madlipz In An English Oral Communication Classroom: A Case Study In Universiti Malaysia Sabah, Malaysia. International Journal Of Education, Psychology and Counselling (IJEPC), 6(41), 1-13. https://doi.org/10.35631/IJEPC.641001

Chen, K. T. C. (2020). University efl students' use of online english information searching strategy. Iranian Journal of Language Teaching Research, 8(1), 111-127.

Falloon, G. (n.d.). Inside the Virtual Classroom: Student Perspectives on Affordances and Limitations. 108-126.

Ismail, N., \& Albakri, I. S. M. A. (2012). An Analysis of ESL Students' Attitude and Interest Towards Learning to Write Essays Using Selected Online Writing Links and Resources. International Journal Of Knowledge, Culture \& Change Management, 11(6), 187-198.

Ismail, N., Hussin, S., \& Darus, S. (2013). The Effects of IQ-Write Program Online Composing Guide towards ESL Tertiary Students' Writing Performance and Interest. $8(4)$.

Lee, K. W., Said, N., \& Tan, C. K. (2016). Exploring the affordances of The Writing Portal (TWP) as an online supplementary writing platform (for the special issue of GLoCALL 2013 and 2014 conference papers). Computer Assisted Language Learning, 29(6), 1116-1135. https://doi.org/10.1080/09588221.2016.1172644

Margaryan, A., Littlejohn, A., \& Vojt, G. (2011). Computers \& Education Are digital natives a myth or reality? University students' use of digital technologies. Computers \& Education, 56(2), 429-440. https://doi.org/10.1016/j.compedu.2010.09.004

Popescu, E. (2012). Providing collaborative learning support with social media in an integrated environment. World Wide Web, 17(2), 199-212. https://doi.org/10.1007/s11280-012-0172-6

Rahim, S. A., Osman, W. H., Musa, M. A. H., \& Rahman, N. D. (2021). Students' Online Learning Readiness amid Covid 19 Outbreak: MCO Phase 1. International Journal of Education, Psychology and Counseling (IJEPC), 6(41), 160-171. https://doi.org/10.35631/IJEPC.641012

Tobi, B., Osman, W. H., Bakar, A. L. A., \& Othman, I. W. (2021). A Case Study On Students' Reasons For Not Switching On Their Cameras During Online Class Sessions. International Journal Of Education, Psychology and Counselling (IJEPC), 6(41), 216-224. https://doi.org/10.35631/IJEPC.641016

Trang, N. M. (2020). Designing a Rhizomatic Online Personal Learning Environment Model to Improve University Students' Academic Listening Skills. International Journal of 


\section{International Journal of

Volume 6 Issue 43 (November 2021) PP. 110-121

DOI 10.35631/IJEPC.643010

Special Issue: Issues and Challenges in English Education English Language and Literature Studies, 9(4), 286-304. https://doi.org/10.18488/journal.23.2020.94.286.304

Valjataga, T., \& Lannpere, M. (2010). Learner control and personal learning environment: a challenge for instructional design. Interactive Learning Environments, 18(3).

Wellapan, U., \& Liyen, L. (2021). Students' Learning Experience in a Web Design Course using Flipped Classroom Approach in Higher Education. International Journal of Education, Psychology and Counseling (IJEPC), 6(40), 193-209. https://doi.org/10.35631/IJEPC.640016

Yunus, M., Salehi, H., \& Chenzi, C. (2012). Integrating Social Networking Tools into ESL Writing Classroom: Strengths and Weaknesses. 5(8), 42-48. https://doi.org/10.5539/elt.v5n8p42 